\title{
The Effect of Volume of Transaction On The Intention Towards Tax E-filing
}

\author{
Saliza Abdul Aziz ${ }^{2, *}$, and Kamil Md Idris ${ }^{1}$ \\ ${ }^{1}$ Tunku Puteri Intan Safinaz School of Accountacy, Universiti Utara Malaysia, Dean, 06010 UUM \\ Sintok, Kedah, Malaysia \\ ${ }^{2}$ Tunku Puteri Intan Safinaz School of Accountacy, Universiti Utara Malaysia, Senior Lecturer, \\ 06010 UUM Sintok, Kedah, Malaysia
}

\begin{abstract}
Volume of transaction is specifically referring to number of clients or return forms dealing by tax agents/preparers. This variable does play role even though there is less empirical evidence on this matter. This paper is basically to explore the effect of volume of transaction that could possibly influence the acceptance of tax e-filing system as it did in other areas of transaction i.e. court cases. Undoubtedly, it is proved to be significantly influenced the behavioural intention towards tax e-filing acceptability in Malaysia. The tax agents/preparers are randomly selected in this study from the list provided in the Inland Revenue Board of Malaysia (IRBM) website. The responds are analysed via Partial Least Square (PLS) method which produce the significant results among the low and high volume of transaction of tax e-filing which support the fact that volume does matter in the decision of acceptability of tax e-filing system in Malaysia.
\end{abstract}

Keywords: Volume of transaction, Behavioral intention, Tax e-filing.

\section{Introduction}

The practice of using technologies in taxation is not new as tax preparation software have been introduced since 1993, but the submission of the return form is done manually. This is because of the clients' requirement who would desire to have physical copy of return form as well as proof of mailing [1]. In 1997, fully utilized the e-filing system among tax practitioners have pushed the percentage of using the tax e-filing to increase. The acceptance is due to the advantages of e-filing obviously more than the manual system, i.e. more efficient; save time and money; reduce number of errors; attributable to the one time early of figures; and the checks is performed by tax preparation software. As a matter of fact, the tax practitioners become more efficient, effective, progressive and technologically sophisticated. In addition to that because of a large number of clients meaning to have huge volume of transactions, e-filing is considered worth and smart decision in handling clients. In fact, this volume of transaction is seen as one of the reason that influences decision in accepting technology among tax practitioners in the United States. Indirectly, e-filing help in reducing the labor costs; reduce the volume of paperwork; paperless and saves paper, toner and file storage costs that benefits the company and clients in terms of cost saving [2, 3].

* Corresponding author: $\underline{\text { saliza@,uum.edu.my }}$ 
Strengthening the fact, besides the big companies, the United States Judicial Courts also has introduced the e-filing system. This is because the e-filing system could help in reducing the ever-growing caseloads. In average, 35 per cent of documents are filed electronically in federal courts, whereas in bankruptcy courts cases are closer to 60 to 70 per cent [4]. The high volume of transaction or cases is one of the factors that led the courts to embrace the technology. Indeed, more than 70 per cent judges, lawyers and clerks supporting the implementation of the e-filing system in handling the increasing of caseloads as well as volume of paperwork that indirectly improve in job performance [5]. As a matter of fact, judges witness that courts benefited a lot from the e-filing system as it could improve access to information; increase efficiency for clerks; and reduce the amount of storage needed for court records. Besides that, due to simple and available software as well as other facilities needed, i.e. PDF software, scanner and computer, e-filing is seem as the best alternative to get rid from the increasing problem of managing caseloads. In addition, less effort is required to educate the related parties has attract the users to accept the system introduced.

The significant effect of volume of transaction that could influence the acceptance of e-filing system is well known. However, there is less evidence or study conducted on this matter to conclude the relationship of this element towards a behavioral intention to accept a new technology. Thus, the objective of this paper is to provide an evidence on the relationship between volume of transaction and behavioral intention in accepting tax efiling among tax agents/preparers in Malaysia.

\section{Previous studies}

Reports from the United States clearly pictured the scenario of accepting e-filing system that is due to the ability to improve performance expectancy and less effort requirement with facilities available. Unfortunately, support on the level of significant effect of volume of transaction on behavioral intention is empirically unknown. Thus, there is a need to conduct study to test the element of volume of transaction on behavioral intention for future reference.

This variable does play role even though there is less empirical evidence on this matter. It is because big companies as well as courts that overload with work and cases preferred to change to e-filing system in order to overcome their inefficiency problem [2, 4, 5]. Thus, there is a possibility of having a significant effect between volume of transaction and acceptance of tax e-filing. However, there is less evidence or study conducted on this matter to prove the relationship towards a behavioral intention to accept a new technology. Hence, the same effect is predicted in tax e-filing scenario in Malaysia where workload or increasing in volume of transaction could possibly affect the work performance. Then, the intention to use the tax e-filing is directed. Moreover, the effectiveness and efficiency of tax e-filing and be able to improve performance with less effort required is not influenced the intention to adopt tax e-filing system without any pressure from the volume of transaction. This condition is also predicted even when facilities available to ease the tax agents/preparers, tax e-filing is not the alternative until volume of transaction really affected the work performance. Thus, the following hypotheses are derived:

$H_{1}$ : The influence of performance expectancy on behavioral intention toward tax e-filing among tax agents/preparers will be moderated by volume of transaction. 
$\mathrm{H}_{2}$ : The influence of effort expectancy on behavioral intention toward tax e-filing among tax agents/preparers will be moderated by volume of transaction.

$\mathrm{H}_{3}$ : The influence of facilitating conditions on behavioral intention toward tax efiling among tax agents/preparers will be moderated by volume of transaction.

\section{Methodologies}

The dependent variable of this research is behavioral intention of accepting e-filing technology. Behavioral intention is the degree to which the tax agents/preparers intend to use the technology of e-filing in preparing and submission of clients' return form [6,7]. It is crucial to study on the intention as employees and organization acceptance could improve technology efficiency and effectiveness [8]. The independent variables are performance expectancy, effort expectancy, social influence, facilitating conditions and perceived value. In addition to the independent variables, the related moderating variable to the research conceptual framework is volume of transaction. Considering the intervention introduced in TAM3 as moderator is purposely to test the significant of those variables in the Unified Theory of Acceptance and Usage of Technology (UTAUT) model. In fact, Venkatesh [7] give a thought on the design of interventions in UTAUT model as it could give an idea for managers in assessing the intention of adopting new technology introduced and help in increasing user acceptance. Thus, the introduction of this variable as moderator could provide explanation on the effectiveness and efficiency of the variables if introduced as intervention in a future study.

In total, there are 1,871 tax agents/preparers officially register with IRBM scattered in the 15 different states in Malaysia. However, the sample size are limited to 714 which taken into consideration of an additional 70 per cent from the recommended size, i.e. 420 tax agents/preparers as according to the table suggested by Krejcie and Morgan [9]. Tax agents/preparers are considered the sample instead of the corporate taxpayers/clients. This is because freedom in choosing the medium of transaction on tax filed to IRBM is fully given by the corporate taxpayers/clients to the tax agents/preparers. Indeed, the influence or factors from point of view corporate taxpayers/clients are not considered.

The questionnaire that is design using 7-point Likert scale is sent via mail to respondents who are selected randomly using simple random sampling technique throughout Malaysia. The selection is made based on the list developed using SPSS software, which excluded the tax agents/preparers who have been participated during the Delphi and pilot test. The statistical tool applied in the result analysis is Structural Equation Modeling (SEM) with additional supports from Partial Least Squares (PLS) and Bootstrapping.

\section{Findings and discussions}

Volume of transaction is one of the new introduced moderators in this research model. This moderator is analyzed via bootstrapping approach as it is in the form of non-continuous scale. The parameter is estimated based on ML estimation derived on 500 usable bootstrap samples. In the process of analysis, two bootstrap samples are unused because a solution is not found. The output tree that represents the estimation of standard error of each loading parameter for this model is attached in the appendix. 
Indeed, compared to the original samples' ML standard error estimation (i.e. S.E. S.E. Column), the approximate standard error of the bootstrapping is within the acceptance level, i.e. small from the original samples. On the other hand, the bias results that are the difference of mean between the bootstrap and the original at estimations show that there is no bias due to low differences reported. As for the goodness-of-fit indices, the standardized estimations are almost within the acceptable range. The absolute fitness reported for group one that consist of 60 or less clients is above 0.08 (i.e. RMSEA $=0.094$ ). The incremental fit is above i.e. CFI is above 0.9 (0.928), TLI is 0.914 and IFI is 0.930 . The parsimonious fitness also shows an acceptable level, which the ratio is below five, i.e. 1.617 with degree of freedom of 174. As for group two where the number of clients are above 60, the absolute fitness reported is above 0.08 (i.e. RMSEA $=0.099$ ). The incremental fit is above, i.e. CFI is almost 0.9 (0.893), TLI is 0.871 and IFI is 0.895 . The parsimonious fitness also shows an acceptable level, which the ratio is below five, i.e. 2.574 with degree of freedom of 174 . The indication of significance level for volume of transaction is very much depends on the chi square and degree of freedom values. The basis of comparison is between the constraint and unconstraint models for each group on each construct. Indeed, the degree of freedom with a difference of one and chi square difference of above 3.84 for each group on each constructs ensured the moderation is significant.

Table 1 and 2 contains the standardized parameter estimates (chi square and degree of freedom), standardized indirect effects for all constructs and its effect on the interaction of volume of transaction. Basically, the three hypotheses reported, i.e. $H_{1} H_{2}$ and $H_{3}$ indicate having significance effect and successfully moderate the direct relationship between exogenous and endogenous. This relationship simply means that volume of transaction does moderate the influence of performance expectancy, effort expectancy and facilitating condition. Specifically, the volume of transaction is tested via multigroup estimation to determine which group of volume, i.e. high or low is more pronounced in giving group effect for the moderator variable. The group that is determined from the standardized beta estimate (slope) indicates that high volume of transaction give more impact on performance expectancy and effort expectancy rather than low volume of transaction group (Table 2). As for the facilitating condition, low group of transaction is more pronounced in affecting the direct relationship of the constructs (Table 1). In addition, the analysis also pointed out the significant effect of volume of transaction in social influence and perceived value constructs (Table 1 and 2). On the whole model, high volume of transaction is affected the relationship toward behavioral intention more pronounced. The ability to explain the relationship of the whole model of behavioral intention towards tax e-filing acceptability is increased slightly to 52.8 per cent. The increment of 0.2 per cent in the power of explained suggest that volume of transaction does improve the best model.

Table 1

Hypothesis testing result of volume of transaction (Group 1: Low volume)

\begin{tabular}{|c|c|c|c|c|c|c|c|}
\hline Нуро- & Relationship & \multicolumn{2}{|c|}{ Constraint } & \multicolumn{2}{|l|}{ Unconstraint } & \multirow[t]{2}{*}{ Estimate } & \multirow[t]{2}{*}{ Result } \\
\hline & & $\mathrm{x}^{2}$ & $\mathrm{DF}$ & $\mathrm{x}^{2}$ & $\mathrm{DF}$ & & \\
\hline$H_{l}:$ & PE* Volume $\rightarrow$ BI & 285.936 & 175 & 281.417 & 174 & .191 & $\mathrm{~S}$ \\
\hline \multirow[t]{2}{*}{$\mathrm{H}_{2}$ : } & EE* Volume $\rightarrow$ BI & 281.832 & 175 & 281.417 & 174 & 1.223 & NS \\
\hline & SI* Volume $\rightarrow$ BI & 295.581 & 175 & 281.417 & 174 & -.156 & $\mathrm{~S}$ \\
\hline \multirow[t]{2}{*}{$H_{3}:$} & $\mathrm{FC}^{*}$ Volume $\rightarrow \mathrm{BI}$ & 288.582 & 175 & 281.417 & 174 & -.868 & $\mathrm{~S}$ \\
\hline & $\mathrm{PV}^{*}$ Volume $\rightarrow \mathrm{BI}$ & 285.915 & 175 & 281.417 & 174 & -.057 & $\mathrm{~S}$ \\
\hline
\end{tabular}

Notes: $* * * \mathrm{p}<0.001,{ }^{* *} \mathrm{p}<0.05,{ }^{*} \mathrm{p}<0.1, \mathrm{~S}=$ Significance, NS=Not Significance 
Table 2

Hypothesis testing result of volume of transaction (Group 2: High volume)

\begin{tabular}{clcccccc}
\hline $\begin{array}{c}\text { Hypo- } \\
\text { thesis }\end{array}$ & Relationship & \multicolumn{2}{c}{ Constraint } & Unconstraint & Estimate & Result \\
\hline & & \multicolumn{2}{c}{$\mathrm{x}^{2}$} & $\mathrm{DF}$ & $\mathrm{x}^{2}$ & $\mathrm{DF}$ & \\
\hline$H_{1}:$ & $\mathrm{PE}^{*}$ Volume $\rightarrow \mathrm{BI}$ & 451.997 & 175 & 447.872 & 174 & .624 & $\mathrm{~S}$ \\
$H_{2}:$ & $\mathrm{EE}^{*}$ Volume $\rightarrow \mathrm{BI}$ & 462.945 & 175 & 447.872 & 174 & .458 & $\mathrm{~S}$ \\
& $\mathrm{SI}^{*}$ Volume $\rightarrow \mathrm{BI}$ & 468.300 & 175 & 447.872 & 174 & -.174 & $\mathrm{~S}$ \\
$H_{3}:$ & $\mathrm{FC}^{*}$ Volume $\rightarrow \mathrm{BI}$ & 458.209 & 175 & 447.872 & 174 & -.201 & $\mathrm{~S}$ \\
& $\mathrm{PV}^{*}$ Volume $\rightarrow \mathrm{BI}$ & 463.517 & 175 & 447.872 & 174 & -.198 & $\mathrm{~S}$ \\
\hline
\end{tabular}

Notes: $* * * \mathrm{p}<0.001,{ }^{* *} \mathrm{p}<0.05,{ }^{*} \mathrm{p}<0.1, \mathrm{~S}=$ Significance, NS=Not Significance

\section{Conclusions}

Empirically, the research's finding indicates that tax e-filing intention does influence by the number of clients. Undeniable, the perceived value that tax agents/preparers expect from tax e-filing, i.e. save time, effort and cost, has encouraged them to accept the system. This research somehow as to support the element of volume in taxation point of view is successfully achieved its purpose. However, further study should be carried out to strongly support the difference behavioral intention between low and high volume of transaction. This is basically due to differences in significance level achieved between the two groups especially in low group of volume. As expected, the performance expectancy, effort expectancy, social influence, facilitating conditions and perceived value factors are definitely influenced the intention of tax agents/preparers with large number of clients. However, in considering effort expectancy, the tax agents/preparers with low group of clients refused to accept the tax e-filing. Indeed, this volume of transaction factor is need to be emphasized and focused as one of moderating factor and test or include in any study related to new technology introduce in future. This is due to its contribution that possibly plays some role in decision making in choosing any technology application. However, this factor is rarely tested and in reality not much reference on this constructs.

\section{References}

1. Warkentin, M., et al., Encouraging Citizen Adoption of e-Government by Building Trust. Journal of Electronic Markets, 2002. 12(3): p. 157-162.

2. Anderson, T., M. Fox, and B.N. Schwartz, History and trends in e-filing: A survey of CPA Practitioners. The CPA Journal, 2005: p. 66-69.

3. Saman, W.S.W.M. and A. Haider, E-Shariah in Malaysia: Technology Adoption Within Justice System. Transforming government: People, Process \& Policy, 2013. 7(2): p. 256-276.

4. $\quad$ Krause, J., E-filing made easy. ABA Journal, 2003: p. 68.

5. Anonymous, Legal group expects e-filing increase. The Information Management Journal, 2005: p. 12.

6. Davis, F.D., Perceived Usefulness, Perceived Ease of Use and User Acceptance of Information Technology. MIS Quarterly, 1989. 13(3): p. 319-340.

7. Venkatesh, V., et al., User Acceptance of Information Technology: Toward a Unified View. MIS Quarterly, 2003. 27(3): p. 425-478.

8. Anderson, J.E., P.H. Schwager, and R.L. Kerns, The Drivers for Acceptance of Tablet PCs by Faculty in a College of Business. Journal of Information Systems Education, 2006. 17(4): p. 429-440.

9. Krejcie, R.V. and D.W. Morgan, Determining Sample Size for Research Activities. Educational and Psychological Measurement, 1970. 30: p. 607-610. 